\title{
Seeking rents in the shadow of Coase
}

\author{
Giuseppe Dari-Mattiacci · Sander Onderstal • \\ Francesco Parisi
}

Received: 2 September 2007 / Accepted: 25 November 2008 / Published online: 5 December 2008 (C) The Author(s) 2008. This article is published with open access at Springerlink.com

\begin{abstract}
In this paper, we study a two-stage rent-seeking game. In the first stage, contestants compete à-la-Tullock; in the second stage, the winner can resell the rent à-la-Coase. We consider a complete information Tullock game in which the contestants have different
\end{abstract}

The authors would like to thank two anonymous referees, Lloyd Cohen, Ben Depoorter, Bruno Frey, David Haddock, Tom Hazlett, Joris van Hoboken, Bruce Kobayashi, Peter Menell, Ilia Rainer, Hans-Bernd Schäfer, William F. Shughart II, Gordon Tullock, and the participants in the 2008 annual meeting of the American Law and Economics Association at NYU, the 2006 Erasmus Law and Economics Workshop at Hamburg University, the 2006 annual meeting of the Public Choice Society in New Orleans, the 2006 annual meeting of the Canadian Law and Economic Association at the University of Toronto, and seminars at Ghent University, University of Zurich, St. Thomas University, Institute for Information Law at the University of Amsterdam, George Mason University School of Law, University of Texas School of Law, and University of Minnesota Department of Applied Economics for helpful comments.

G. Dari-Mattiacci gratefully acknowledges the financial support from the NWO grant 016.075.332.

S. Onderstal gratefully acknowledges the financial support from the NWO grant 453.03.606.

G. Dari-Mattiacci $(\bowtie)$

ACLE and Tinbergen Institute, University of Amsterdam, Roetersstraat 11, 1018WB Amsterdam, The Netherlands e-mail: gdarimat@uva.nl url: http://ssrn.com/author=333631

\section{S. Onderstal}

Amsterdam School of Economics and Tinbergen Institute, University of Amsterdam, Roetersstraat 11, 1018WB Amsterdam, The Netherlands

e-mail: a.m.onderstal@uva.nl

url: http://ssrn.com/author=342318

F. Parisi

School of Law, University of Minnesota, 229 South 19th Ave., Minneapolis, MN 55455, USA

e-mail: parisi@umn.edu

url: http://ssrn.com/author=227722

F. Parisi

Department of Economics, University of Bologna, Via Zamboni, 33, 40126 Bologna, Italy 
valuations for the rent. The analysis focuses on the ex ante effects of a secondary market on efforts, payoffs, rent-dissipation and rent-misallocation. We show that the secondary market, while correcting possible misallocations, may exacerbate rent dissipation. In some situations, the increase in rent dissipation more than offsets the allocative advantage, so that a secondary market might reduce welfare. We further show how the effect of ex post tradeability on welfare depends on the parties' bargaining power and valuations of the rent, also considering the case of endogenous bargaining power.

Keywords Rent-seeking · Asymmetric rent valuations · Rent-dissipation · Rent-misallocation

\section{JEL Classification C72 $\cdot$ D72}

\section{Introduction}

Once upon a time, two knights were jousting for the hand (and the love) of a princess. The knights were of equal strength, valor, and courage, but one of them only aimed at the kingdom, while the other also secretly loved the princess. The literature on rent-seeking has analyzed these types of contests and has pointed to the fact that the participants will dissipate socially valuable resources in the attempt to win the prize. However, this literature has focused mainly on rent-dissipation and has given little credit to the idea that there is an additional social cost associated with such tournaments: the princess may marry the wrong knight.

When parties have different valuations of the rent, allocative inefficiencies may come about in addition to rent-dissipation. Rent-seeking contests do not guarantee that rents will be appropriated by parties who value them the most (Lott 1987; Hurley 1998; Nti 1999). Glaeser and Luttmer (2003) show, for instance, that misallocation of housing occurs in controlled markets, where the allocation of apartments does not fully rely on the price system.

Rent-misallocations amount to a social cost but, unlike rent-dissipation, these forms of allocative inefficiency can be corrected after the fact. While in our example the knights cannot subsequently reallocate the princess, Coase (1960) pointed out that other sought-after rights can be traded ex post. ${ }^{1}$ Real life examples of tradeable rents range from homestead property to emission permits, transferable public procurement contracts, and the new European Internet domain names dot-eu. ${ }^{2}$ In the case of tradeable rights, if a low-valuing party

\footnotetext{
${ }^{1}$ The possibility of ex post bargaining differs from the possibility of an ex ante collusion between the rentseekers. If rent seekers could collude ex ante, the entire rent-seeking problem would disappear. Rents would be allocated through bargaining, without dissipation. In several real-world settings, however, participants in a rent-seeking game do not have an opportunity to bargain or collude with one another prior to the rent-seeking contest. Impediments to bargain may be the result of legal prohibitions (e.g., prohibition of collusion between bidders in a public procurement contest) or factual impediments (e.g., large transaction costs in contests with a large number of competitors). In several such situations, these impediments to bargaining are reduced or eliminated after the contest. Thus, for example, a winning bidder is allowed to resell or subcontract to a losing competitor. Similarly, impediments to bargaining or collusion among a large number of contestants due to high transaction costs are likely to be reduced after the rent-seeking contest.
}

${ }^{2}$ See the information available at www.eurid.eu. 
wins the contest he is likely to sell the prize to a high-valuing party, thereby correcting rent-misallocation. ${ }^{3}$

While correcting misallocations, ex post resale may increase rent-dissipation. The prospect of ex post resale makes the prize more appealing to low-valuing parties. Even parties with very low valuations may find the contest profitable if they can sell the prize to high-valuing parties at a price that may be significantly higher than their own valuation. In some situations, the possibility for ex post resale might be the only reason why parties engage in rent-seeking activities.

Examples on point are common. We routinely observe individuals with no interest in sports or music engaging in scalping of tickets before a decisive game or an important concert. Likewise, in the dot-com era, domain names have often been purchased by individuals with no intrinsic valuation, solely attracted by resale opportunities. An example is found in Avery Dennison Corp. v. Sumpton, ${ }^{4}$ where a company had registered over 12,000 Internet domain names for no other apparent purpose than that of reselling them. Countless other firms or individuals have made fortunes by simply reselling Internet domain names. ${ }^{5}$ By inducing larger investments by low-valuing parties, the possibility of ex post resale may exacerbate the rent-dissipation problem. Conversely, forbidding resale, as it is for the Australian dot-com-dot-au domain names, ${ }^{6}$ might generate large misallocation costs.

In this paper, we explore the effects of secondary markets in a rent-seeking model. We observe three possible outcomes: (i) ex post resale reduces rent-dissipation; (ii) ex post resale increases rent-dissipation while still reducing total social costs; (iii) ex post resale increases rent-dissipation to the point that also total social costs increase, since the increase in dissipation exceeds the reduction in misallocation. The outcome is shown to depend on the relative bargaining power of the parties. ${ }^{7}$ If the bargaining power of the low-valuing party is limited, a secondary market reduces social costs.

Our model shows that the possibility of ex post resale has ambiguous effects on incentives, equilibrium payoffs and rent-dissipation. Without a secondary market, not all parties necessarily participate in the rent-seeking contest: parties with the lowest valuations might stay out of the game. Among the participating parties, those with higher valuations invest more and achieve higher winning probabilities. Instead, with a secondary market, all parties participate and exert the same level of effort, splitting the rent equally among them. Payoffs follow a similar, but not identical pattern, the payoff of the party with the highest value being always larger than that of the other parties.

\footnotetext{
${ }^{3}$ Even if the prize itself is nontransferable, such as some licences, permits, or import quotas, de facto transferability may result from the sale of the whole firm, the sale of the products to an intermediary, or subcontracting. In the case of import quotas, for example, an authorized importer could either distribute the product to consumers directly or sell the entire stock - and corresponding monopoly rent- to a more effective distributor.

${ }^{4} 999$ F.Supp. 1337 C.D.Cal., 1998.

${ }^{5}$ See http://money.cnn.com/magazines/business2/business2_archive/2007/06/01/100050989/index.htm? postversion $=2007052205$.

${ }^{6}$ See the 2005 Australian Domain Name Administrator's Policy on Clarification of Domain Name LicenceProhibition on Sale of Domain Names, at: http://www.auda.org.au/policies/auda-2005-05/.

${ }^{7}$ Bargaining power can be understood in very general terms. In fact, in the model, the price lies between the seller's and the buyer's valuations. Our comparative statics results are parametrized on the actual price chosen by the parties between these two boundaries. We refer in the paper to bargaining power as a determinant of such choice; however, our results are more general and apply irrespective of the notion employed to select the price.
} 
We further demonstrate that a secondary market is usually ${ }^{8}$ desirable from the point of view of low-valuing parties, since it allows them to resell at a higher price than their valuation. High-valuing parties however do not necessarily benefit from the prospect of ex post reallocations. This is because the introduction of a secondary market gives the party with the highest value an opportunity to purchase the right should he fail in the rent-seeking contest, but also increases the competition that he faces from low-valuing contestants.

On a theoretical level, our analysis brings together insights and results from rent-seeking and property rights theory, showing that there is an important link between the initial acquisition of a property right (e.g., homesteading) ${ }^{9}$ and its derivative circulation (e.g., sale). The rent-seeking literature (Tullock 1967; Krueger 1974; Posner 1975) ${ }^{10}$ initially considered parties competing for the appropriation of a commonly valued rent, a setting in which the final allocation is efficient by hypothesis. Asymmetries between the parties' valuations have subsequently been studied in relation to the parties' efforts, the resulting dissipation, and entry in the contest (Hillman and Riley 1989; Nti 1999). ${ }^{11}$ We bring the Coase theorem (Coase 1960) to bear on the analysis, allowing the parties to negotiate after the initial phase of rentseeking. Combining Tullock's insight that competition for rents generates rent-dissipation with Coase's argument that markets correct any initial misallocation, we show that, in some situations the increase in rent-dissipation more than offsets the allocative gains of resale, so that a secondary market results in an increased social loss. ${ }^{12}$

Our paper brings to light another contradiction with existing literature. According to the Coase theorem, an efficient allocation of resources is achievable independently of the initial allocation of rights and distribution of the bargaining surplus between the parties. We show instead that the efficiency of the outcome depends on the distribution of the bargaining

\footnotetext{
${ }^{8}$ This result holds if the price is exogenously determined.

${ }^{9}$ A well-know example is the 1862 Homestead Act, concerning the new territories of the west of the United States. Most legal systems include similar rules of 'first come, first served' regulating how property on things that belong to nobody (res nullius) and abandoned things (res derelictae) is to be assigned. It has been observed that rules of first possession (such as 'first come, first served' and 'finders, keepers') generate rent-seeking incentives in the initial allocation of property rights (Barzel 1974) leading to wasteful expenditures in the appropriation of such rights also in the form of too fast exploitation (Barzel 1968; Dasgupta and Stiglitz 1980; Anderson and Hill 1990; Lueck 1995). Mortensen (1982) shows that the ex post distribution of the surplus affects ex ante incentives to invest in mating and racing games but does not discuss the issue of ex post trade.

${ }^{10}$ See also Congleton et al. (2008); Higgins et al. (1985); Epstein and Nitzan (2007); Lockard and Tullock (2001).

${ }^{11}$ Contests with asymmetric valuations are also studied in Leininger (1993) and Baik (1994). Moreover, Baye et al. (1993), Che and Gale (1998), Goeree et al. (2005), and Onderstal (2007) study the effect of asymmetric valuations in a completely discriminatory contest, i.e., the highest bidder wins with probability equal to 1 . None of these contributions studies the effects of ex post trade of the rent. For a recent review of the literature on (rent-seeking) contests see Tollison (2003) and Epstein and Nitzan (2007). For analyses of standard auctions with resale, see Garratt and Tröger (2006) and Hafalir and Krishna (2008) and the references contained therein.

${ }^{12}$ Some previous contributions also emphasize the perverse effects of trading possibilities. Jacklin (1987) shows that the presence of liquid equity markets undermines the role of banks in reducing liquidity risk. Literature on incomplete contracts (Grossman and Hart 1986) emphasizes the importance of rights that cannot be transferred by contract and the effects that the allocation of such rights has on the parties' investments in the relationship. Our perspective is different, since we analyze the investments of the parties prior to the allocation of such rights.
} 
surplus - a distributive aspect of the Coase theorem, which is generally considered irrelevant for the efficient allocation of resources. ${ }^{13}$

We are not the first to study the effect of a secondary market on welfare. In Zardkoohi and Pustay (1989) and Gahvari (1989), the total social loss is unaffected by ex post resale. This result derives from an assumption of total rent-dissipation by the winning party only (the losing party incurs no costs). If the low-valuing party secures the rent and resale is not allowed, the misallocation cost is equal to the difference in the parties' valuations and rent-dissipation is equal to the low value. With a secondary market, the misallocation cost disappears, but now the low-valuing party is willing to invest as much as the high-valuing party. That is, rent-dissipation increases exactly by the difference in the parties' valuations. Thus, a secondary market does not affect social welfare. In our model, this scenario is a special case of the more general situation in which the parties exert effort but do not necessarily dissipate the full rent. Gahvari (1989) further conjectures that when both parties incur costs or when dissipation is less than full, a secondary market might reduce social welfare. In our paper, we derive new results that partially confirm Gahvari's conjecture, identifying conditions under which social welfare decreases. Our analysis, however, shows that under some parameter values, social welfare increases when secondary markets are introduced. In addition, we examine the effect of a secondary market on parties' participation choices.

Like us, Suen (1989) finds that a secondary market may both increase and decrease welfare. He does so in a model of rent-seeking through waiting (essentially a model of rationing). He assumes that multiple parties compete with one another for the appropriation of a transferable rent (rationed commodity). In Suen's model, the variance in waiting costs determines whether a secondary market has a positive or negative effect on welfare. In contrast, in our model, the key variables are bargaining power and the distribution of the parties' values, while the cost of rent-seeking effort is the same for all parties.

In addition to ex post resale, a corrective tax may realign private and social incentives in rent-seeking contests. Like us, Epstein and Nitzan (2002) examine a situation in which the parties' asymmetric valuations can generate misallocation. They find that a minimal asymmetry in the parties' valuations is a necessary condition for a corrective tax to be effective. In our framework, instead, ex post resale always corrects misallocation, while rent-dissipation might increase or decrease as a result of ex post resale. Moreover, unlike the literature just revised, we allow the price in the secondary market to depend on the efforts exerted by the parties in the preliminary rent-seeking face of the game.

Our paper is organized as follows. In Sect. 2, we present our baseline model: a two-party rent-seeking contest where the contestants have different valuations of the contested rent. In Sect. 3, we begin by analyzing the rent-seeking contest without a secondary market. Next, we consider rent-seeking with a secondary market. We assess the effects of a secondary market on incentives and social costs of rent-seeking by comparing the outcome of rentseeking with and without a secondary market. In Sect. 4, we extend the analysis to the $N$-party case. We conclude in Sect. 5 with some qualifications of our analysis, possible refinements, and ideas for future research. Proofs are relegated to the Appendix.

\footnotetext{
${ }^{13}$ Discussing the use of property rules and liability rules for the internalization of external costs, Bebchuk (2001) observes that the choice of remedy affects the ex post distribution of resources with ex ante effects on the levels of the parties' investments in their property. However, he does not discuss the effects on ex ante incentives to invest in rent-seeking.
} 


\section{The model}

We consider a rent-seeking contest between two ${ }^{14}$ risk-neutral parties $L$ and $H .{ }^{15}$ Let $B_{i} \geq 0$ denote party $i$ 's rent-seeking expenditures and $V_{i}$ his valuation of the rent, with $i \in\{L, H\}$. The parties are completely informed about each others' values. Following the conventional Tullock (1980) framework, ${ }^{16}$ party $i$ 's success function is given by

$$
S_{i}=\frac{B_{i}^{r}}{B_{i}^{r}+B_{j}^{r}}
$$

with $\{i, j\}=\{L, H\}$. The success function can be interpreted either as the probability to win the entire rent or as the share of the appropriated rent. ${ }^{17}$ As usual, $r$ is an index of the parties' marginal return to effort. ${ }^{18}$ Accordingly, party $i$ 's payoff is given by

$$
U_{i}=S_{i} V_{i}-B_{i}
$$

Parties differ in their valuation of the rent $V_{i}$. For simplicity, we assume that there are two types of parties: a low-valuing party $L$ with value $V_{L} \geq 0$ and a high-valuing party $H$ with value $V_{H} \geq V_{L}$. To simplify notation, we introduce a variable measuring the level of asymmetry between the parties' valuations, $\gamma \equiv \frac{V_{L}}{V_{H}}$. The value of $\gamma$ ranges $0 \leq \gamma<1$, approaching 1 if the parties have similar valuations of the rent and approaching 0 if the parties' valuations differ substantially.

In the following, we will focus on situations where an equilibrium in pure strategies exists. This is guaranteed when the parties face decreasing, constant or moderately increasing marginal returns to effort: $0<r<1+\gamma^{r}$ (Nti 1999). ${ }^{19}$ It is easy to show that the upper bound for $r$ increases in $\gamma$ and is at least 1 and at most 2 .

When parties have heterogeneous valuations of the rent, losses from inefficient allocations of the rent should be considered in addition to the traditional problems of rentdissipation. The misallocation losses can be viewed as an opportunity cost due to the fact that the rent could have been put to a higher-value use. Accordingly, we define two loss

\footnotetext{
${ }^{14}$ In Sect. 4, we consider an extension of the model to $N$ parties.

${ }^{15}$ See Allard (1988), Nti (1999), Lockard and Tullock (2001), Epstein and Nitzan (2007), and Konrad (2007) on this model.

${ }^{16}$ In reality, the splitting of a prize between two contestants may not follow Tullock's sharing rule and may take up a whole range of possible functional forms. We follow Tullock's traditional framework since it allows for an easier comparison of our results with those of the existing rent-seeking literature and for an explicit calculation of equilibrium values, but see also Hirshleifer (1989). Most of the results presented in this paper could also be obtained with a more general success function.

${ }^{17}$ Assuming risk neutrality, these two interpretations are functionally equivalent. Thus, hereinafter, we refer indifferently to either interpretation. If the success function is interpreted as a share of the prize, it allows for multiple, partial winners and may generate additional social loss due to property fragmentation (Parisi 2002).

${ }^{18}$ Alternatively, $r$ can be seen as the discriminative power of the auction.

${ }^{19} \mathrm{Nti}$ (1999) writes this condition as $V_{L}^{r}+V_{H}^{r}>r V_{H}^{r}$.
} 
variables: ${ }^{20}$ the rent-dissipation, given by the sum of the parties' efforts

$$
D=B_{L}+B_{H}
$$

and the rent-misallocation, given by the share of the rent appropriated by the low-valuing party scaled by the valuation difference

$$
M=S_{L}\left(V_{H}-V_{L}\right) .
$$

Obviously, in the special case of parties with equal valuations of the rent, the misallocation is equal to zero.

\section{Analysis}

\subsection{Rent-seeking without a secondary market}

The equilibrium for the rent-seeking contest with asymmetric parties is as follows:

Proposition 1 (Nti 1999) The two-party rent-seeking contest without a secondary market has a unique pure Nash equilibrium, in which the parties' efforts are

$$
\begin{aligned}
B_{L}^{*} & =r \frac{\gamma^{r}}{\left(1+\gamma^{r}\right)^{2}} V_{L}, \quad \text { and } \\
B_{H}^{*} & =r \frac{\gamma^{r}}{\left(1+\gamma^{r}\right)^{2}} V_{H} .
\end{aligned}
$$

The parties' expected payoffs are

$$
\begin{aligned}
U_{L}^{*} & =\frac{\gamma^{2 r}+(1-r) \gamma^{r}}{\left(1+\gamma^{r}\right)^{2}} V_{L}, \quad \text { and } \\
U_{H}^{*} & =\frac{1+(1-r) \gamma^{r}}{\left(1+\gamma^{r}\right)^{2}} V_{H} .
\end{aligned}
$$

The social cost of rent-seeking is given by the sum of rent-dissipation and rentmisallocation. Using the results of the previous proposition, it is possible to calculate these costs, expressed in (2) and (3). ${ }^{21}$

\footnotetext{
${ }^{20}$ Note that we assume throughout that the parties' rent-seeking efforts have purely redistributive effects. For an analysis of rent-seeking contests where rent-seeking effort is socially productive see Dari-Mattiacci and Parisi (2005) and Dari-Mattiacci et al. (2007) and the conclusions at the end of this paper. The notion of 'contest efficiency' (CE) introduced by Hurley (1998, p. 291) can be written in terms of dissipation and misallocation as follows: $C E=1-\frac{D+M}{V_{H}}$. The reader can easily apply this transformation to compare our results. As from Hurley's analysis, it follows from our analysis that only minimizing rent dissipation may not minimize total social costs in the presence of rent misallocation.

${ }^{21}$ It is shown in Nti (1999) that the low-valuing party's effort increases in his own valuation and decreases in the valuation of the other party. In contrast, effort by the high-valuing party increases in both parties' valuations. This can be easily understood. An increase in the valuation of the low-valuing party makes the contest more symmetric, inducing both parties to exert more effort. Consequently, the winning probabilities converge towards $\frac{1}{2}$. In contrast, an increase in the valuation of the high-valuing party makes the contest more asymmetric, to the advantage of the high-valuing party, who increases his effort. Instead, the low-valuing party decreases his effort and the winning probabilities diverge.
} 
Corollary 1 In the two-party rent-seeking contest without a secondary market, the rentdissipation is

$$
D^{*}=r \frac{\gamma^{r}}{\left(1+\gamma^{r}\right)^{2}}(1+\gamma) V_{H}
$$

and the rent-misallocation is

$$
M^{*}=\frac{\gamma^{r}}{1+\gamma^{r}}(1-\gamma) V_{H} .
$$

\subsection{Rent-seeking with a secondary market}

The presence of asymmetric rent valuations generates allocative inefficiencies. In some situations, possible misallocations of the rent can however be corrected through ex post resale. Low-valuing winners can sell the rent to their high-valuing opponents. We consider the general case in which the winner of the rent and the party who wishes to buy it bargain with one another and reallocate the rent, splitting the contractual surplus according to their respective bargaining power. Whenever a reallocation of the rent takes place, the price paid by the high-valuing party to the low-valuing party is $V_{L} \leq P \leq V_{H}$. The resale price $P$ can be read as an index of the parties' relative bargaining power: the higher the price, the greater the bargaining power of the low-valuing party and vice versa.

We assume that the relative bargaining power depends on the parties' efforts in the preceding rent-seeking contest. More in particular, we take the resale price to be a function of the low-valuing party's winning probability $P=p\left(S_{L}\right),{ }^{22}$ where $p(\cdot)$ is a twice differentiable function and $P^{\prime}=p^{\prime}\left(S_{L}\right)=\frac{\partial P}{\partial S_{L}}$. Since we focus on situations where an equilibrium in pure strategies exists, we assume that $P^{\prime}$ is sufficiently small.

Note that the case where $P^{\prime}=0$ corresponds to parties considering the investments in the contest as sunk costs once they start bargaining. In that case, a unique outcome will be reached, independent of efforts in the contest, similarly to the outcome of standard bargaining models, such as the ones by Nash (1950) and Rubinstein (1982).

In contrast, if the resale price depends on the parties' efforts, ${ }^{23} P^{\prime}<0$ implies that the price decreases in the low-valuing party's effort and increases in the high-valuing party's effort. This situation could represent a case where larger expenditures in rent-seeking in the first stage weaken the low-valuing party's bargaining power or where a high-valuing party, who has spent large resources in the first stage of the game and failed to appropriate the rent, may be willing to pay a higher price to secure the rent in the secondary market.

Finally, $P^{\prime}>0$ implies that the price increases in the low-valuing party's effort and decreases in the high-valuing party's effort. This setting could describe a situation where a

\footnotetext{
${ }^{22}$ Note that this formulation captures the idea that the price depends on the divergence between the parties' efforts. Note also that, since $S_{H}=1-S_{L}$, our model captures situations where the price is a function of both the high and low party's winning probabilities.

${ }^{23}$ The marginal effects of the parties' efforts on price are as follows: since $\frac{\partial P}{\partial B_{L}}=\frac{\partial P}{\partial S_{L}} \frac{\partial S_{L}}{\partial B_{L}}$ and $\frac{\partial S_{L}}{\partial B_{L}}>0$, we have sign $\frac{\partial P}{\partial B_{L}}=\operatorname{sign} \frac{\partial P}{\partial S_{L}}$. Likewise, since $\frac{\partial P}{\partial B_{H}}=\frac{\partial P}{\partial S_{L}} \frac{\partial S_{L}}{\partial B_{H}}$ and $\frac{\partial S_{L}}{\partial B_{H}}<0$, we have $\operatorname{sign} \frac{\partial P}{\partial B_{H}}=\operatorname{sign}\left(-\frac{\partial P}{\partial S_{L}}\right)$. Note that in our analysis the price varies in different directions as the parties' efforts increase. This is due to the choice of the probability of winning as an argument of the price function. A more general model should encompass the possibility for the parties' efforts to affect the price in the same direction, such as in situations where the willingness-to-pay and willingness-to-accept for the rent is endogenously determined by effort expenditures in the rent-seeking game.
} 
low-valuing party has expended large amounts of effort to appropriate the rent and is unwilling to resell the rent at a low price or could refer to a high-valuing party who, having expended large outlays of effort in the first stage, may be unable to expend additional large amounts for purchasing the rent in the secondary market (e.g., due to budget constraints or increasing marginal costs of capital).

In this setting, the low-valuing party will choose his effort level considering the price that he could extract from the high-valuing contestant in the ex post resale. The possibility of ex post resale affects the payoffs as follows:

$$
\begin{aligned}
U_{L} & =S_{L} P-B_{L}, \quad \text { and } \\
U_{H} & =S_{H} V_{H}+S_{L}\left(V_{H}-P\right)-B_{H} \\
& =S_{H} P-B_{H}+\left(V_{H}-P\right) .
\end{aligned}
$$

The above formulations of the parties' payoffs highlight the interesting features of rentseeking with a secondary market. The parties' payoffs remain asymmetric, because the parties' actual gains from the game depend on their respective bargaining power. Unless the low-valuing party has full bargaining power and is able to extract the entire surplus from the other party $\left(P=V_{H}\right)$, the high-valuing party will still have a larger payoff from the game if both invest the same amount. This is due to the fact that the high-valuing party appropriates the difference between his valuation and the price paid to his opponent. The derivatives of the utilities are as follows: ${ }^{24}$

$$
\begin{aligned}
\frac{\partial U_{L}}{\partial B_{L}} & =\frac{\partial S_{L}}{\partial B_{L}}\left(P+S_{L} P^{\prime}\right)-1, \\
\frac{\partial U_{H}}{\partial B_{H}} & =-\frac{\partial S_{L}}{\partial B_{H}}\left(P+S_{L} P^{\prime}\right)-1 .
\end{aligned}
$$

Note that if $B_{L}=B_{H}, \frac{\partial S_{L}}{\partial B_{L}}=-\frac{\partial S_{L}}{\partial B_{H}},{ }^{25}$ so that $\frac{\partial U_{L}}{\partial B_{L}}=\frac{\partial U_{H}}{\partial B_{H}}$. This yields that the parties' equilibrium levels of efforts are the same and can be calculated, as in a traditional Tullock game, by reference to the price $P$ rather than to the different valuations of the contested rent.

Therefore, the parties' incentives to invest in rent-seeking effort are symmetric, despite the asymmetry persistent in the parties' payoffs. The intuition is that the high-valuing party will always obtain his high-valued rent $V_{H}$, whether through direct appropriation in the primary contest, or through ex post reallocation in the secondary market. By introducing a secondary market, parties with asymmetric payoffs end up playing symmetrically. Holding $V_{H}$ constant, the difference for a high-valuing party between success and failure only depends on the price to be paid to the low-valuing party, if the latter successfully appropriates the rent. If the high-valuing party wins the rent-seeking game, he avoids the payment of $P$.

Equating the expressions in (6) to zero, the following proposition can be readily derived; a double asterisk denotes equilibrium values with a secondary market:

Proposition 2 The two-party rent-seeking contest with a secondary market has a pure Nash equilibrium, in which the parties' efforts are

$$
B_{L}^{* *}=B_{H}^{* *}=\frac{r}{4}\left(P^{* *}+\frac{1}{2} P^{* *}\right)
$$

\footnotetext{
${ }^{24}$ Note that rearranging the expression above we have $U_{H}=V_{H}-S_{L} P-B_{H}$.

${ }^{25}$ We have $\frac{\partial S_{i}}{\partial B_{i}}=-\frac{\partial S_{j}}{\partial B_{i}}=\frac{r S_{i} S_{j}}{B_{i}}$, with $\{i, j\}=\{L, H\}$.
} 
and the parties' expected payoffs are

$$
\begin{aligned}
U_{L}^{* *} & =\frac{2-r}{4} P^{* *}-\frac{r}{8} P^{\prime * *}, \quad \text { and } \\
U_{H}^{* *} & =V_{H}-\frac{2+r}{4} P^{* *}-\frac{r}{8} P^{* *}
\end{aligned}
$$

where $P^{* *}=p\left(\frac{1}{2}\right)$ is the equilibrium resale price and $P^{* *}=p^{\prime}\left(\frac{1}{2}\right)$.

Note that, notwithstanding the equivalence in the parties' effort, both parties would benefit from the fact that the resale price decreases with the low-valuing party's effort and increase with the high-valuing party's effort, as both payoffs increase as $P^{\prime}$ becomes small and possibly negative. A consequence of the equivalence between the parties' incentives is that the social cost can be expressed as follows:

Corollary 2 In the two-party rent-seeking contest with a secondary market, the rentdissipation is

$$
D^{* *}=\frac{r}{2}\left(P^{* *}+\frac{1}{2} P^{* *}\right)
$$

and the rent-misallocation is

$$
M^{* *}=0 .
$$

Note that if $P^{\prime}=0$, which is the case if the price $P$ is taken as exogenous, the parties' equilibrium efforts and payoffs and the rent-dissipation are as in the traditional Tullock game.

\subsection{Comparison}

The possibility of ex post resale alters the parties' equilibrium levels of effort and consequently their payoffs. A secondary market transforms the game in two ways. On the one hand, a secondary market makes the game symmetric in terms of the parties' incentives; on the other hand, a secondary market changes the magnitude of the rent for which the parties compete.

The former effect is clear if we examine the ratio between the parties' efforts. Without a secondary market, the parties invest in the rent-seeking game in proportion to their valuations: $\frac{B_{L}^{*}}{B_{H}^{*}}=\gamma$. In contrast, with a secondary market, the parties' efforts are the same $\frac{B_{L}^{* *}}{B_{H}^{* *}}=1$. However, as we have observed, also the prize implicitly changes. This gives rise to the following questions: Will a party increase or decrease his effort when ex post resale is allowed? How will the social cost of rent-seeking change?

Likewise, ex post resale affects the parties' payoffs. Both with and without a secondary market, the high-valuing party earns more than the low-valuing party. However, while without a secondary market this difference depends on the asymmetry between the valuations $\left(\frac{U_{L}^{*}}{U_{H}^{*}}<\gamma\right),{ }^{26}$ with a secondary market the high-valuing party's advantage $\left(\frac{U_{L}^{* *}}{U_{H}^{* *}}<1\right)$ depends on the parties' bargaining power. This observation suggests that the parties' payoffs are

${ }^{26}$ This inequality derives from proposition 1 and $0<\frac{\gamma^{2 r}+(1-r) \gamma^{r}}{1+(1-r) \gamma^{r}}<1$. 
affected in different ways by a secondary market. Will both parties benefit from the introduction of trade?

In the following we address these questions. Let us start with the effort and payoff of the low-valuing party and define two threshold levels of $P$ :

$$
\begin{aligned}
P_{B_{L}} & \equiv \frac{4 \gamma^{r}}{\left(1+\gamma^{r}\right)^{2}} V_{L}-\frac{1}{2} P^{\prime * *}, \text { and } \\
P_{U_{L}} & \equiv \frac{4 \gamma^{r}}{\left(1+\gamma^{r}\right)^{2}} \frac{1-r+\gamma^{r}}{2-r} V_{L}+\frac{r}{4-2 r} P^{* *} .
\end{aligned}
$$

Proposition 3 In the two-party rent-seeking contest, the low-valuing party exerts more (less) effort with a secondary market than without if and only if the equilibrium price is higher (lower) than $P_{B_{L}}$ :

$$
B_{L}^{* *}>(<) B_{L}^{*} \quad \text { iff } P^{* *}>(<) P_{B_{L}} .
$$

The low-valuing party obtains a larger (smaller) payoff with a secondary market than without if and only if equilibrium price is higher (lower) than $P_{U_{L}}$ :

$$
U_{L}^{* *}>(<) U_{L}^{*} \quad \text { iff } P^{* *}>(<) P_{U_{L}} \text {. }
$$

The following corollary shows that in the case of a constant resale price, a secondary market unambiguously improves the position of the low-valuing party, who exerts more effort and is able to appropriate a larger share of the rent through ex post negotiations with his high-valuing opponent. A variation in the relative bargaining power of the parties, $P$, will only quantitatively affect this result in the sense that a larger $P$ further improves the position of the low-valuing party.

Corollary 3 In the two-party rent-seeking contest, if $P^{\prime * *}=0$, the low-valuing party exerts more effort and obtains a larger payoff with a secondary market than without:

$$
\begin{aligned}
& B_{L}^{* *}>B_{L}^{*}, \quad \text { and } \\
& U_{L}^{* *}>U_{L}^{*} .
\end{aligned}
$$

This suggests that the position of the low-valuing party is negatively affected by the possible effect of the high-valuing party's effort on price. The position of the high-valuing party, instead, depends on the parties' relative bargaining power, even if the resale price is constant. Let us define two additional threshold levels of $P$ :

$$
\begin{aligned}
P_{B_{H}} & \equiv \frac{4 \gamma^{r}}{\left(1+\gamma^{r}\right)^{2}} V_{H}-\frac{1}{2} P^{\prime * *}, \quad \text { and } \\
P_{U_{H}} & \equiv \frac{4 \gamma^{r}}{\left(1+\gamma^{r}\right)^{2}} \frac{1+r+\gamma^{r}}{2+r} V_{H}-\frac{r}{4+2 r} P^{\prime * *} .
\end{aligned}
$$

Proposition 4 In the two-party rent-seeking contest, the high-valuing party exerts more (less) effort with a secondary market than without if and only if the equilibrium price is higher (lower) than $P_{B_{H}}$ :

$$
B_{H}^{* *}>(<) B_{H}^{*} \quad \text { iff } P^{* *}>(<) P_{B_{H}} .
$$


The high-valuing party obtains a smaller (larger) payoff with a secondary market than without if and only if the equilibrium price is higher (lower) than $P_{U_{H}}$ :

$$
U_{H}^{* *}<(>) U_{H}^{*} \quad \text { iff } P^{* *}>(<) P_{U_{H}} .
$$

The effect of a secondary market on the high-valuing party's payoff may vary due to the presence of two countervailing effects. First, a secondary market makes it possible for the rent to be purchased ex post by the high-valuing party. This lowers the high-valuing party's need to invest in the rent-seeking contest for a direct appropriation of the rent. Second, the possibility of ex post resale makes the low-valuing party behave more aggressively. The net impact of these two countervailing effects depends on the parties' bargaining power. If the high-valuing party has a sufficiently strong bargaining position (low $P$ ), the first effect will dominate over the second, reducing his incentives to compete and improving his payoff. If the low-valuing party has strong bargaining power (high $P$ ), the second effect prevails and we have the paradoxical result that giving the high-valuing party the opportunity to buy the rent in the secondary market worsens his position.

By the same token, a secondary market may increase or decrease rent-dissipation, depending on the parties' bargaining power. Consider two limit cases: When the high-valuing party has full bargaining power $\left(P=V_{L}\right)$, the two contestants compete as if they were both low-valuing parties. Hence, the opportunity for ex post reallocation of the rent reduces the equilibrium level of dissipation. In contrast, when the low-valuing party has full bargaining power $\left(P=V_{H}\right)$, both parties compete for the same higher value. Evidently, in this case the dissipation is larger with a secondary market. As above, let us define a new threshold level of $P$ :

$$
P_{D} \equiv \frac{2 \gamma^{r}(1+\gamma)}{\left(1+\gamma^{r}\right)^{2}} V_{H}-\frac{1}{2} P^{\prime * *} .
$$

The following proposition follows by comparing (4) and (7).

Proposition 5 In the two-party rent-seeking contest, rent dissipation is larger (smaller) with a secondary market than without if and only if the equilibrium price is higher (lower) than $P_{D}$ :

$$
D^{* *}>(<) D^{*} \quad \text { iff } P^{* *}>(<) P_{D}
$$

Although misallocation is totally eliminated by a secondary market, the possibility for ex post reallocation may actually increase the total social cost of rent-seeking if the probability of misallocation is relatively small. The following proposition shows that this can indeed be the case if the resale price is sufficiently large and can be easily derived by comparing (4), (5), and (7). The new threshold is:

$$
P_{D+M} \equiv \frac{2 \gamma^{r}(1+\gamma)}{\left(1+\gamma^{r}\right)^{2}}\left(1+\frac{\left(1+\gamma^{r}\right)(1-\gamma)}{r(1+\gamma)}\right) V_{H}-\frac{1}{2} P^{\prime * *}
$$

Proposition 6 In the two-party rent-seeking contest, the total social loss is larger (smaller) with a secondary market than without if and only if the equilibrium price is higher (lower) than $P_{D+M}$ :

$$
D^{* *}+M^{* *}>(<) D^{*}+M^{*} \quad \text { iff } P^{* *}>(<) P_{D+M} .
$$


Table 1 Effort, payoffs and social cost for the various threshold levels of $P^{* *}$ for $P^{\prime * *}=0$

\begin{tabular}{|c|c|c|c|c|c|c|}
\hline \multirow{2}{*}{ 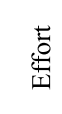 } & $\begin{array}{c}\text { Low-valuing } \\
\text { party }\end{array}$ & \multirow{2}{*}{$\begin{array}{c}B_{L}{ }^{* *}>B_{L}{ }^{*} \\
B_{H}{ }^{* *}<B_{H}{ }^{*}\end{array}$} & \multirow{2}{*}{$\begin{array}{l}B_{L}^{* *}>B_{L}^{*} \\
B_{H}^{* *}<B_{H}^{*}\end{array}$} & \multirow{2}{*}{$\begin{array}{l}B_{L}^{* *}>B_{L}^{*} \\
B_{H}^{* *}<B_{H}^{*}\end{array}$} & \multirow{2}{*}{$\begin{array}{l}B_{L}^{* *}>B_{L}^{*} \\
B_{H}^{* *}>B_{H}^{*}\end{array}$} & \multirow{2}{*}{$\begin{array}{l}B_{L}^{* *}>B_{L}{ }^{*} \\
B_{H}^{* *}>B_{H}{ }^{*}\end{array}$} \\
\hline & 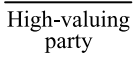 & & & & & \\
\hline \multirow{2}{*}{ 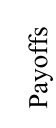 } & $\begin{array}{l}\text { Low-valuing } \\
\text { party }\end{array}$ & $U_{L}^{* *}>U_{L}^{*}$ & $U_{L}^{* *}>U_{L}^{*}$ & $U_{L}^{* *}>U_{L}^{*}$ & $U_{L}^{* *}>U_{L}^{*}$ & $U_{L}^{* *}>U_{L}^{*}$ \\
\hline & 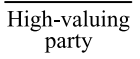 & $U_{H}{ }^{* \prime}>U_{H}{ }^{*}$ & $U_{H}{ }^{*}>U_{H}{ }^{*}$ & $U_{H}^{* *}<U_{H}^{*}$ & $U_{H}^{* *}<U_{H}^{*}$ & $U_{H}^{* *}<U_{H}^{*}$ \\
\hline \multirow{2}{*}{$\begin{array}{l}0 \\
\frac{0}{0} \\
\frac{0}{0} \\
\frac{\pi}{0} \\
\text { n }\end{array}$} & Dissipation & $D^{* *}<D^{*}$ & $D^{* *}>D^{*}$ & $D^{* *}>D^{*}$ & $D^{* *}>D^{*}$ & $D^{* *}>D^{*}$ \\
\hline & $\begin{array}{c}\text { Total social } \\
\text { loss }\end{array}$ & $D^{* *}+M^{* *}<D^{*}$ & $D^{* *}+M^{* *}<D^{*}$ & $D^{* *}+M^{* *}<D^{*}$ & $D^{* *}+M^{* *}<D^{*}$ & $D^{* *}+M^{* *}>D^{*}$ \\
\hline
\end{tabular}

It can be easily shown that for all $0<\gamma<1$,

$$
P_{B_{L}}<P_{D}<P_{B_{H}}<P_{D+M}
$$

The ranking of $P_{U_{L}}$ and $P_{U_{H}}$ relative to the other thresholds are ambiguous in the general case. However, if $P^{\prime * *}=0$, it can be shown that $P_{U_{H}}$ falls between $P_{D}$ and $P_{B_{H}}$, while, from Corollary 3 , the threshold $P_{U_{L}}$ is always satisfied.

Table 1 illustrates the previous results, showing how the parties' effort and payoff and the social loss change at the various threshold levels of $P$ if $P^{* *}=0$. The low-valuing party always increases his effort when trade is allowed. For values of $P^{* *}$ less than $P_{D}$, the increase in the low-valuing party's effort is offset by a decrease in the high-valuing party's effort. As a result, a secondary market reduces rent dissipation. For values of $P$ greater than $P_{D}$, dissipation increases with a secondary market as the low-valuing party increases his effort more than the high-valuing party reduces his own. For even higher values of $P^{* *}\left(P^{* *}>P_{B_{H}}\right)$, also the higher-valuing party increases his effort further increasing rent-dissipation and eventually bringing it to a point (when $P^{* *}>P_{D+M}$ ) where the allocative advantage of a secondary market is offset by the increased rent-dissipation. Note that $P_{U_{H}}<P_{B_{H}}$ : the high-valuing party exerts more effort in order compensate for the smaller payoff earned in comparison with the situation without secondary market.

Figure 1 illustrates how the threshold levels of $P^{* *}$ change when $\gamma$ changes for $r=1$ and $P^{* * *}=0$. Note that only values above or on the forty-five-degree line are admissible, since $P^{* *} \geq V_{L}$. The figure shows that the parties' relative bargaining power and the asymmetry in their valuations are somewhat complementary. If there is little asymmetry (large $\gamma$ ), then, even if the low-valuing party has strong bargaining power, the presence of a secondary market is likely to improve welfare. In contrast, if the parties' valuations are very asymmetric (small $\gamma$ ), then the secondary market worsens social welfare even for relatively low values of the low-valuing party's bargaining power.

The figure also illustrates that three outcomes are possible. First, for values of the parties' bargaining power $P$ and asymmetry in the valuation $\gamma$ in the area to the right of the curve $P_{D}$, the secondary market reduces both rent dissipation and rent misallocation. Second, for values of $P^{* *}$ between $P_{D}$ and $P_{D+M}$, the secondary market increases rent dissipation but not enough to offset the reduction in rent misallocation. This area is further divided into three parts by the curves for $P_{U_{H}}$ and $P_{B_{H}}$. In the region above [below] $P_{U_{H}}$, the high-valuing party earns less [more] with a secondary market than without. In turn, in the area above $P_{B_{H}}$, 
Fig. 1 Threshold levels of $P^{* *}$ for different values of gamma, for $r=1$ and $P^{* *}=0$

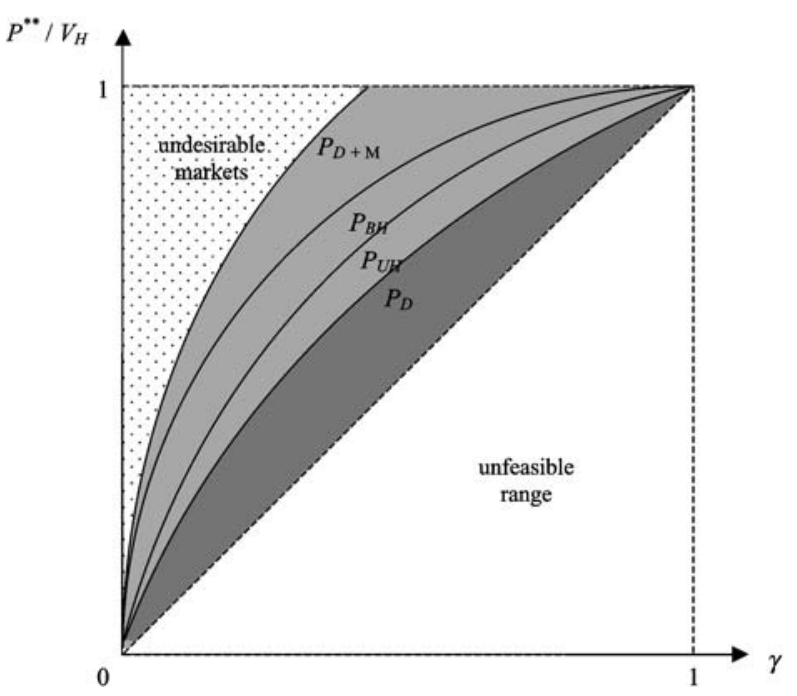

the high-valuing party invests more when a secondary market is operating. Third, in the area above $P_{D+M}$, the increase in the high-valuing party's effort brings dissipation to a point at which the allocative advantage of trade is completely lost and social welfare decreases. If the parties' marginal return to effort increases, the curves depicted in Fig. 1 shift downwards, as the following corollary shows.

Corollary 4 In the two-party rent-seeking contest:

$$
\frac{\partial P_{B_{L}}}{\partial r}, \frac{\partial P_{D}}{\partial r}, \frac{\partial P_{B_{H}}}{\partial r}, \frac{\partial P_{D+M}}{\partial r}<0 .
$$

For $P^{* * *}=0$ we also have $\frac{\partial P_{U_{L}}}{\partial r}<0$ and $\frac{\partial P_{U_{H}}}{\partial r}<0$.

In other words, increasing $r$ makes the threshold levels of $P$ that we have identified more easily satisfiable. This in turn implies that for larger $r$ it is more likely that the presence of a secondary market will worsen social welfare. This finding can be explained by observing that when $r$ is large, competition in the rent-seeking game is already fierce without a secondary market. The introduction of a secondary market is likely to make it even more fierce. This is because large marginal returns to effort make a low-valuing party increase his expenditure more when trade is allowed. In turn, the high-valuing party is more likely to increase his own effort when facing an already tough competitor. The result is that increased competition (higher $r$ ) generates rent dissipation losses that are more likely to offset the allocative gains. This result implies that secondary markets are more desirable when the parties competing in a rent-seeking contest are "weak", that is, they have small marginal return to effort.

Corollary 5 In the two-party rent-seeking contest:

$$
\begin{aligned}
\frac{\partial P_{B_{L}}}{\partial P^{\prime * *}}, \frac{\partial P_{D}}{\partial P^{* * *}}, \frac{\partial P_{U_{H}}}{\partial P^{\prime * *}}, \frac{\partial P_{B_{H}}}{\partial P^{\prime * *}}, \frac{\partial P_{D+M}}{\partial P^{\prime * *}} & <0, \\
\frac{\partial P_{U_{L}}}{\partial P^{\prime * *}} & >0 .
\end{aligned}
$$


This corollary suggests that-with the exception of $P_{U_{L}}$, which moves in the opposite direction $-P$ is more likely to be above the thresholds the more the effort by the low-valuing party increases the price while effort by the high-valuing party decreases it. The fact that the low-valuing party's effort has a positive effect on price, while the impact of the high-valuing party's effort is negative, makes the rent-seeking stage more fierce as both parties have a reason to exert more effort. This makes the equilibrium level of effort with a secondary market go up, along with rent dissipation and the total social loss. The payoffs of the parties go down accordingly, due to the increased outlays of effort.

\section{$4 N$ parties}

In this section, we extend our analysis to a contest with $N>2$ parties, labeled $i=1, \ldots, N$, such that

$$
V_{1} \geq V_{2} \geq \cdots \geq V_{N} \geq 0 .
$$

We assume that $V_{2}>0$, so that there are at least two parties with a genuine interest in the rent. For simplicity, in this section we restrict the analysis to the special case of constant marginal return to effort $r=1$ and constant exogenous price $P$. Party $i$ 's payoff is given by

$$
U_{i}=\frac{B_{i}}{\sum_{j=1}^{N} B_{j}} V_{i}-B_{i}, \quad \text { with } i=1, \ldots, N .
$$

As before, we will study the complete information case in which parties are commonly informed about each others' values. With $N$ parties, rent-dissipation and rent-misallocation are defined as follows:

$$
\begin{aligned}
D & \equiv \sum_{i=1}^{N} B_{i}, \quad \text { and } \\
M & \equiv \sum_{i=1}^{N} \frac{B_{i}}{\sum_{j=1}^{N} B_{j}}\left(V_{1}-V_{i}\right) .
\end{aligned}
$$

4.1 Rent-seeking without a secondary market

We will first examine the equilibrium properties of the rent-seeking contest in a situation without a secondary market: final allocations of the rent are determined by the rent-seeking contest, without an opportunity for ex post transfers. Let $\hat{V}_{k}$ denote the harmonic mean of the highest $k$ values:

$$
\hat{V}_{k} \equiv \frac{k}{\sum_{j=1}^{k} \frac{1}{V_{j}}}, \quad k=1, \ldots, N .
$$

Define $n$ as the smallest integer for which

$$
V_{n+1} \leq \frac{n-1}{n} \hat{V}_{n}
$$

Hillman and Riley (1989) show that only the $n$ parties with the highest values will be active in equilibrium. An immediate consequence of this observation is that, in contrast to the two-party case, some parties may decide to expend no effort in equilibrium. Stein (2002) derives equilibrium efforts, and Matros (2006) shows that the equilibrium is unique. 
Proposition 7 (Matros 2006) The N-party rent-seeking contest without a secondary market has a unique pure Nash equilibrium, in which the parties' efforts are

$$
B_{i}^{*}= \begin{cases}\frac{n-1}{n} \hat{V}_{n}-\frac{1}{V_{i}}\left(\frac{n-1}{n} \hat{V}_{n}\right)^{2} & \text { if } i=1, \ldots, n, \\ 0 & \text { if } i=n+1, \ldots, N\end{cases}
$$

and the parties' expected payoffs are

$$
U_{i}^{*}= \begin{cases}\frac{1}{V_{i}}\left(V_{i}-\frac{n-1}{n} \hat{V}_{n}\right)^{2} & \text { if } i=1, \ldots, n, \\ 0 & \text { if } i=n+1, \ldots, N .\end{cases}
$$

From this, we can readily derive rent-dissipation and misallocation losses in equilibrium.

Corollary 6 In the N-party rent-seeking contest without a secondary market, the rentdissipation is

$$
D^{*}=\frac{n-1}{n} \hat{V}_{n}
$$

and the rent-misallocation is

$$
M^{*}=(n-1) \hat{V}_{n}-\sum_{i=2}^{n} V_{i}
$$

\subsection{Rent-seeking with a secondary market}

Now, consider the situation where parties can transfer the rent in the secondary market after the initial rent-seeking contest. Assume that the secondary market always reallocates rents in the hands of the highest valuing contestant, party 1 . We assume that all selling parties have the same bargaining power, that the resale price is exogenous and lies somewhere between the highest and the second-highest valuations of the contestants, $P \in\left[V_{2}, V_{1}\right]$. The selling price is in fact always at least $V_{2}$, given that party 2 would be willing to buy or keep the rent if the price is less than $V_{2}$.

Similar to the two-party case, the possibility of ex post resale transforms a situation with asymmetric incentives into one with symmetric incentives. In particular, the possibility of resale affects the parties' payoffs as follows:

$$
\begin{aligned}
U_{i} & =\frac{B_{i}}{\sum_{j=1}^{N} B_{j}} P-B_{i}, \quad \text { for } i=2, \ldots, N, \quad \text { and } \\
U_{1} & =\frac{B_{1}}{\sum_{j=1}^{N} B_{j}} V_{1}+\left(1-\frac{B_{1}}{\sum_{j=1}^{N} B_{j}}\right)\left(V_{1}-P\right)-B_{1} \\
& =\frac{B_{1}}{\sum_{j=1}^{N} B_{j}} P-B_{1}+\left(V_{1}-P\right) .
\end{aligned}
$$

The first term on the right-hand-side of (9) refers to the situation where party 1 wins in the rent-seeking stage, while the second term refers to the bargaining stage. As in the two-party case, incentives and equilibrium strategies are symmetric. We have the following result. 
Proposition 8 The N-party rent-seeking contest with a secondary market has a unique pure Nash equilibrium, in which the parties' efforts are

$$
B_{i}^{* *}=\frac{N-1}{N^{2}} P, \quad \text { for } i=1, \ldots, N
$$

and the parties' expected payoffs are

$$
\begin{aligned}
U_{i} & =\frac{1}{N^{2}} P, \quad \text { for } i=2, \ldots, N, \quad \text { and } \\
U_{1} & =\frac{1}{N^{2}} P+\left(V_{1}-P\right) .
\end{aligned}
$$

Corollary 7 In the $N$-party rent-seeking contest with a secondary market, the rentdissipation is

$$
D^{* *}=\frac{N-1}{N} P
$$

and the rent-misallocation is

$$
M^{* *}=0 .
$$

Observe that with a secondary market, all parties are active in equilibrium, in contrast to what we observed in the absence of a secondary market.

\subsection{Comparison}

How does the availability of a secondary market affect efforts, expected payoffs, misallocation and rent-dissipation? As in the two-party case, low-valuing parties benefit from a secondary market. More precisely, we observe that some of the low-valuing parties that remained inactive when there were no resale opportunities join the contest when resale opportunities are introduced. These are contestants that do not have a sufficiently genuine interest in the rent to enter the contest in the first case, who become attracted by resale opportunities, entering the market in the second case. With a secondary market these parties exert strictly positive efforts and obtain positive payoffs.

For active parties with a genuine interest in the rent, the effects of a secondary market are ambiguous. For parties $2, \ldots, n$, this can be immediately seen by comparing (8) and (10). If $N$ increases, the payoffs with a secondary market converge to zero, while they are strictly bounded away from zero without a secondary market for constant $n$. In other words, if sufficiently many inactive parties become active with a secondary market, a secondary market worsens the position of those parties who were already active. The opposite result obtains if the selling party has strong bargaining power ( $P$ is close to $V_{1}$ ) and $V_{1}$ is large.

Analogously, party 1 is worse off with a secondary market if $N$ is large relative to $n$ and $P$ is close to $V_{1}$, while a secondary market improves party 1 's payoff if both $P$ and the values of all other parties are close to $V_{2}$. Thus, as in the two-party case, the relative performance of a secondary market for the payoffs of the parties depends on the bargaining power of the selling party, reflected in the resale price $P$.

The effect of a secondary market on rent-dissipation also depends on the bargaining power of the selling party. As in the two-party case, we can define a threshold for the selling 
party's bargaining power:

$$
P_{D} \equiv \frac{n-1}{n} \frac{N}{N-1} \hat{V}_{n}
$$

Proposition 9 In the N-party rent-seeking contest, rent dissipation is larger (smaller) with a secondary market than without if and only if the equilibrium price is higher (lower) than $P_{D}$ :

$$
D^{* *}>(<) D^{*} \quad \text { iff } P>(<) P_{D} \text {. }
$$

The following corollary provides sufficient conditions for a secondary market to increase or decrease rent-dissipation. If the bargaining power of the seller is weak (reflected in a low $P$ ), and most parties are already active in the situation without a secondary market, a secondary market has a negative effect on dissipation. In other words, the higher the relative value of parties $2, \ldots, N$ (reflected in a high number of active parties $n$ and a high $\hat{V}_{N}$ ) the more likely it is that the opportunity to resell reduces dissipation.

Corollary 8 In the $N$-party rent-seeking contest, rent-dissipation is larger with a secondary market than without if the resale price is higher than $\hat{V}_{n}$ :

$$
D^{* *}>D^{*} \quad \text { if } P>\hat{V}_{n} \text {. }
$$

Rent-dissipation is smaller with a secondary market than without if the resale price is lower than $\hat{V}_{N}$ and $\hat{V}_{N}$ is larger than $V_{2}$ :

$$
D^{* *}<D^{*} \text { if } N=n, P<\hat{V}_{N} \text { and } \hat{V}_{N}>V_{2} \text {. }
$$

Let us now consider the relative performance of the situations with and without a secondary market in terms of the total social costs $D+M$. Recall that

$$
D^{*}+M^{*}=\frac{n^{2}-1}{n} \hat{V}_{n}-\sum_{i=2}^{n} V_{i}
$$

and

$$
D^{* *}+M^{* *}=D^{* *}=\frac{N-1}{N} P .
$$

Thus, the threshold value for $P$ can be expressed as follows:

$$
P_{D+M} \equiv \frac{N}{N-1}\left(\frac{n^{2}-1}{n} \hat{V}_{n}-\sum_{i=2}^{n} V_{i}\right) .
$$

Proposition 10 In the $N$-party rent-seeking contest, the total social loss is larger (smaller) with a secondary market than without if and only if the resale price is higher (lower) than $P_{D+M}$ :

$$
D^{* *}+M^{* *}>(<) D^{*}+M^{*} \quad \text { iff } P>(<) P_{D+M} .
$$

The expression for $P_{D+M}$ and the above proposition provide us with an indication of what are the likely situations where total social loss is actually increased by the introduction of a secondary market: $n$ is small relative to $N$ (only a small fraction of genuine contestants 
who are active without a secondary market), and $P$ is close to $V_{1}$ (strong bargaining power of the lower-valuing contestants/sellers). The following corollary makes this intuition more precise.

Corollary 9 In the N-party rent-seeking contest, the total social loss is greater with a secondary market than without one, i.e.,

$$
D^{* *}+M^{* *}>D^{*}+M^{*},
$$

if at least one of the following conditions holds:

1. $P>\frac{N^{2}}{N-1} V_{2}$;

2. $P=V_{1}$, and $n=2$;

3. $P>\frac{N}{N-1}(4-2 \sqrt{3}) V_{1}$, and $n=2$;

4. $V_{1}=V_{2}$, and $n=2$;

5. $V_{1}=V_{2}$ and $N>\frac{n^{2}}{\sum_{i=1}^{n} V_{i}}$.

The above corollary shows that in addition to the bargaining power of the seller, in the $N$-party case also the number of parties who would be inactive without a secondary market becomes relevant. Note that conditions 1,2 , and 3 point to situations where the seller has strong bargaining power. A substantial number of inactive parties without a secondary market is reflected in conditions 2 through 5 above (where "a substantial number" could be as little as one).

In spite of the potential entry of parties without a genuine interest in the $N$-party contest, the result obtained for the two-party case generalizes to the $N$-party case: total social loss may decrease with a secondary market. The following result establishes that a secondary market decreases social loss if $V_{i}$ is close to $V_{2}$ for all $i=3, \ldots, N$ (little dispersion at the bottom) and $P$ is close to $V_{2}$ (little bargaining power of the seller). The intuition behind the first condition is that little dispersion at the bottom implies that all parties are genuine contestants who would be active rent-seekers also in the absence of a secondary market.

Corollary 10 In the $N$-party rent-seeking contest, for all $N, V_{1}$, and $V_{2}<V_{1}$, there is a non-zero mass of parameters $\left(P, V_{3}, \ldots, V_{N}\right)$ in the neighborhood of $P=V_{2}$ and $V_{i}=V_{2}$ for all $i=3,4, \ldots, N$, for which total social cost is reduced by introducing a secondary market:

$$
D^{* *}+M^{* *}<D^{*}+M^{*}
$$

\section{Conclusions}

New dimensions of the rent-seeking problem emerge when rent-seekers have different valuations of the sought-after rent. Rent-seeking contests may serve as valuable mechanisms to force parties to reveal their preferences through investment choices. High-valuing parties will fight more aggressively and will thus have higher probabilities to appropriate the rent. In this sense, rent-seeking contests may play a valuable allocative role. Given the mechanics of rent-seeking contests, however, this allocative role is imperfect and, unlike in all-pay auctions, misallocation remains possible.

In this paper, we have studied the effect of ex post reallocation of the rent on the parties' incentives and total rent-dissipation. According to the Coase theorem, ex post contractual 
solutions correct initial misallocation of resources; thus, whenever the sought-after rent is transferable, the opportunity for ex post reallocation eliminates any misallocation. Transferability, while correcting misallocation problems, may exacerbate rent-dissipation due to an increase in the stakes of the game. We show that the introduction of a secondary market may imply an increase in rent-dissipation or in total social loss. This is particularly the case if parties with low values have strong bargaining power. In contrast, if the bargaining power is on the side of the contestant with the highest value, ex post resale may reduce rent-dissipation and total social loss.

An important policy implication of our analysis is that making ex post transfers illegal may increase welfare. This result sheds light on the unique nature of rent-seeking: markets for rents, unlike traditional markets for goods, are not always desirable. We hence revisit the current wisdom in the literature, identifying the conditions for the desirability (or lack thereof) of legal or institutional restrictions on ex post reallocations of rents. These results shed light on important policy questions and provide insights for the design of rent-seeking contests.

In choosing among alternative ways to reduce the social cost of rent-seeking, policymakers should keep in mind that ex post reallocations may be costly to prohibit. Further, ex post resale restrictions may be circumvented in legal or illegal ways, giving origin to possible second-order dissipation of rent. In all such cases, different mechanisms, such as taxes or auctions, may be capable of generating optimal allocations of the rent in the absence of secondary markets. ${ }^{27}$ These alternative policy choices are not always feasible or can be expensive to implement, and the balancing of costs and benefits among alternatives are at times difficult to evaluate. The solution adopted for the Internet domain names dot-eu, for example, has been to allow trade, and ad hoc rules have been adopted to prevent registration of some domain names by intermediaries for resale purposes. ${ }^{28}$

Further studies should consider the fact that some rent-seeking contests such as patent races are not purely redistributive of existing resources but enhance the value of such resources, with positive externalities for society at large, which might not be entirely captured by the parties. Extensions of this model should also include consideration of other asymmetries between the contestants, such as asymmetries in the parties strength and returns to rent-seeking efforts, studying the interaction of asymmetries in strength and valuation of the rent between the parties. This issue may provide a fertile ground for contract theory scholars to consider the design of alternative mechanisms, to capture the benefits of ex post transferability of the rent, while avoiding the possible increase in rent dissipation evidenced in this paper.

Open Access This article is distributed under the terms of the Creative Commons Attribution Noncommercial License which permits any noncommercial use, distribution, and reproduction in any medium, provided the original author(s) and source are credited.

\footnotetext{
${ }^{27}$ Epstein and Nitzan (2002) consider corrective taxes in rent-seeking contests. For an overview of the large literature on auctions, see, e.g., Krishna (2002).

${ }^{28}$ Some of these rules provide for an initial screening of claims involving, inter alia, trademarks, geographical indications, or designations of origin. After this initial phase (the so-called Sunrise period), dot-eu domain names are allocated on a strict 'first come, first served' basis, which is likely to induce some residual but probably more limited rent-seeking activity.
} 


\section{Appendix}

Proof of Corollary 3 From Propositions 1 and 2, we have $B_{L}^{* *}=\frac{r}{4} P^{* *}>r \frac{\gamma^{r}}{\left(1+\gamma^{r}\right)^{2}} V_{L}=B_{L}^{*}$, because $P^{* *} \geq V_{L}$ and $\frac{\gamma^{r}}{\left(1+\gamma^{r}\right)^{2}}<\frac{1}{4}$. The latter inequality follows because $\gamma^{r} \in[0,1)$ and the function $f(x) \equiv \frac{x}{(1+x)^{2}}$ is strictly increasing for $x \in[0,1)$ with $f(1)=\frac{1}{4}$. Similarly,

$$
\frac{\gamma^{2 r}+(1-r) \gamma^{r}}{\left(1+\gamma^{r}\right)^{2}}<\frac{\gamma^{r}+(1-r) \gamma^{r}}{\left(1+\gamma^{r}\right)^{2}}=\frac{\gamma^{r}}{\left(1+\gamma^{r}\right)^{2}}(2-r)<\frac{1}{4}(2-r) .
$$

Therefore, using $P^{* *} \geq V_{L}$, we obtain $U_{L}^{* *}=\frac{2-r}{4} P^{* *}>\frac{\gamma^{2 r}+(1-r) \gamma^{r}}{\left(1+\gamma^{r}\right)^{2}} V_{L}=U_{L}^{*}$.

Proof of Corollary 4 Note that $\frac{\partial P^{\prime * *}}{\partial r}=\frac{\partial p^{\prime}\left(\frac{1}{2}\right)}{\partial r}=0$. The results follow from the following derivatives:

$$
\begin{aligned}
\frac{\partial P_{B_{L}}}{\partial r} & =4 \gamma^{r} \frac{1-\gamma^{r}}{\left(1+\gamma^{r}\right)^{3}} \ln \gamma V_{L}<0, \\
\frac{\partial P_{D}}{\partial r} & =2 \gamma^{r} \frac{(\gamma+1)\left(1-\gamma^{r}\right)}{\left(1+\gamma^{r}\right)^{3}} \ln \gamma V_{H}<0, \\
\frac{\partial P_{B_{H}}}{\partial r} & =4 \gamma^{r} \frac{1-\gamma^{r}}{\left(1+\gamma^{r}\right)^{3}} \ln \gamma V_{H}<0 .
\end{aligned}
$$

Furthermore, $\operatorname{since} \operatorname{sign}\left(\frac{\partial P_{U_{L}}}{\partial r}\right)=\operatorname{sign}\left(\frac{\partial \ln P_{U_{L}}}{\partial r}\right)$, for $P^{\prime * *}=0$ we have:

$$
\begin{aligned}
\frac{\partial \ln P_{U_{L}}}{\partial r} & =\ln \gamma-2 \frac{\gamma^{r} \ln \gamma}{1+\gamma^{r}}+\frac{\gamma^{r} \ln \gamma-1}{1-r+\gamma^{r}}+\frac{1}{2-r} \\
& =\ln \gamma\left(\frac{1-\gamma^{r}}{1+\gamma^{r}}+\frac{\gamma^{r}}{1-r+\gamma^{r}}\right)-\frac{1-\gamma^{r}}{\left(1-r+\gamma^{r}\right)(2-r)} \\
& <0 .
\end{aligned}
$$

Likewise:

$$
\begin{aligned}
\frac{\partial \ln P_{U_{H}}}{\partial r} & =\ln \gamma-\frac{2 \gamma^{r} \ln \gamma}{1+\gamma^{r}}+\frac{1+\gamma^{r} \ln \gamma}{1+r+\gamma^{r}}-\frac{1}{2+r} \\
& =\frac{\ln \gamma^{r}}{r}\left(\frac{1-\gamma^{r}}{1+\gamma^{r}}+\frac{\gamma^{r}}{1+r+\gamma^{r}}\right)+\frac{1-\gamma^{r}}{\left(1+r+\gamma^{r}\right)(2+r)} \\
& \leq \frac{\ln \gamma^{r}}{r\left(1+r+\gamma^{r}\right)}+\frac{1-\gamma^{r}}{\left(1+r+\gamma^{r}\right)(2+r)} \\
& \leq-\frac{1-\gamma^{r}}{r\left(1+r+\gamma^{r}\right)}+\frac{1-\gamma^{r}}{\left(1+r+\gamma^{r}\right)(2+r)} \\
& <0 .
\end{aligned}
$$


The second inequality follows from the fact that for all $x \in[0,1], \ln x \leq x-1$. The other manipulations are straightforward. Finally, note that we can write $P_{D+M}=P_{D}\left(1+\frac{\left(1+\gamma^{r}\right)(1-\gamma)}{r(1+\gamma)}\right)$. It is easy to verify that $\frac{\partial}{\partial r}\left(\frac{\left(1+\gamma^{r}\right)(1-\gamma)}{r(1+\gamma)}\right)<0$ so that $\frac{\partial P_{D+M}}{\partial r}<0$.

Proof of Corollary 6 The equilibrium rent-dissipation is given by

$$
\begin{aligned}
D^{*} & =\sum_{i=1}^{N} B_{i}^{*}=\sum_{i=1}^{n} B_{i}^{*}=(n-1) \hat{V}_{n}-\sum_{i=1}^{n} \frac{1}{V_{i}}\left(\frac{n-1}{n} \hat{V}_{n}\right)^{2} \\
& =(n-1) \hat{V}_{n}-\frac{n}{\hat{V}_{n}}\left(\frac{n-1}{n} \hat{V}_{n}\right)^{2}=\frac{n-1}{n} \hat{V}_{n} .
\end{aligned}
$$

The equilibrium rent-misallocation is equal to

$$
\begin{aligned}
M^{*} & =\sum_{i=1}^{N} \frac{B_{i}^{*}}{\sum_{j=1}^{N} B_{j}^{*}}\left(V_{1}-V_{i}\right)=\sum_{i=1}^{n} \frac{B_{i}^{*}}{\sum_{j=1}^{N} B_{j}^{*}}\left(V_{1}-V_{i}\right) \\
& =V_{1}-\sum_{i=1}^{n} \frac{B_{i}^{*} V_{i}}{\sum_{j=1}^{N} B_{j}^{*}} \\
& =V_{1}-\sum_{i=1}^{n} \frac{\frac{n-1}{n} \hat{V}_{n} V_{i}-\left(\frac{n-1}{n} \hat{V}_{n}\right)^{2}}{D^{*}} \\
& =V_{1}-\sum_{i=1}^{n} \frac{D^{*} V_{i}-\left(D^{*}\right)^{2}}{D^{*}}=V_{1}-\sum_{i=1}^{n}\left(V_{i}-D^{*}\right) \\
& =(n-1) \hat{V}_{n}-\sum_{i=2}^{n} V_{i} .
\end{aligned}
$$

Proof of Corollary 8 The first result follows because

$$
D^{*}=\frac{n-1}{n} \hat{V}_{n}<\frac{n-1}{n} P \leq \frac{N-1}{N} P=D^{* *} .
$$

With respect to the second result, recall that

$$
V_{i} \leq \frac{n-1}{n} \hat{V}_{n}, \quad i=n+1, \ldots, N .
$$

It follows that

$$
\sum_{j=n+1}^{N} \frac{1}{V_{i}} \geq \sum_{j=n+1}^{N} \frac{n}{(n-1) \hat{V}_{n}}=\frac{(N-n) n}{(n-1) \hat{V}_{n}}
$$

Therefore,

$$
\begin{aligned}
\frac{N-1}{N} \hat{V}_{N} & =\frac{N-1}{\sum_{j=1}^{N} \frac{1}{V_{j}}}=\frac{N-1}{\sum_{j=n+1}^{N} \frac{1}{V_{j}}+\sum_{j=1}^{n} \frac{1}{V_{j}}} \\
& \leq \frac{N-1}{\frac{(N-n) n}{(n-1) \hat{V}_{n}}+\frac{n}{\hat{V}_{n}}}=\frac{(n-1) \hat{V}_{n}}{n} .
\end{aligned}
$$


So, the result follows because

$$
D^{* *}=\frac{N-1}{N} P<\frac{N-1}{N} \hat{V}_{N} \leq \frac{n-1}{n} \hat{V}_{n}=D^{*} .
$$

Proof of Corollary 9 Condition 1 implies

$$
\begin{aligned}
D^{*}+M^{*} & =(n-1)\left(1+\frac{1}{n}\right) \hat{V}_{n}-\sum_{i=2}^{n} V_{i} \\
& =\frac{n^{2}-1}{\sum_{j=1}^{n} \frac{1}{V_{j}}}-\sum_{i=2}^{n} V_{i} \\
& \leq \frac{n^{2}-1}{\frac{n-1}{V_{2}}}-V_{2} \\
& =n V_{2} \leq N V_{2} \\
& <\frac{N-1}{N} P \\
& =D^{* *}+M^{* *} .
\end{aligned}
$$

The first inequality follows because $V_{i} \leq V_{2}$ for all $i \geq 3$. It is easily checked that the third inequality holds true by substituting $P>\frac{N^{2}}{N-1} V_{2}$.

In conditions 2,3 , and $4, n=2$. Total social loss without a secondary market for $n=2$ is given by

$$
D^{*}+M^{*}=\frac{3 V_{1} V_{2}}{V_{1}+V_{2}}-V_{2} .
$$

It is readily established that this expression is maximized with respect to $V_{2}$ for

$$
V_{2}^{*}=(\sqrt{3}-1) V_{1} .
$$

For all $N \geq 3$ and $V_{1}=P$ (the second condition),

$$
\begin{aligned}
D^{*}+M^{*} & \leq \frac{3 V_{1} V_{2}^{*}}{V_{1}+V_{2}^{*}}-V_{2}^{*} \\
& =(4-2 \sqrt{3}) V_{1} \\
& <\frac{N-1}{N} V_{1}=\frac{N-1}{N} P=D^{* *}+M^{* *} .
\end{aligned}
$$

If condition 3 holds true,

$$
D^{*}+M^{*} \leq(4-2 \sqrt{3}) V_{1}<\frac{N-1}{N} P=D^{* *}+M^{* *} .
$$

The first inequality follows from (11), the second by substituting $P>\frac{N}{N-1}(4-2 \sqrt{3}) V_{1}$.

The result with respect to condition 4 immediately follows from the observations that $M^{*}=M^{* *}=0$, and

$$
D^{*}=\frac{1}{2} V_{1}<\frac{N-1}{N} V_{1}=D^{* *} .
$$


The fifth condition implies that $P=V_{1}$ because $V_{1}=V_{2}$. Therefore,

$$
\begin{aligned}
D^{*}+M^{*} & =(n-1)\left(1+\frac{1}{n}\right) \hat{V}_{n}-\sum_{i=2}^{n} V_{i} \\
& \leq(n-1)\left(1+\frac{1}{n}\right) \frac{1}{n} \sum_{i=1}^{n} V_{i}-\sum_{i=2}^{n} V_{i} \\
& =\frac{n^{2}-1}{n^{2}} \sum_{i=1}^{n} V_{i}-\sum_{i=2}^{n} V_{i} \\
& =V_{1}-\frac{1}{n^{2}} \sum_{i=1}^{n} V_{i} \\
& <\frac{N-1}{N} V_{1}=\frac{N-1}{N} P=D^{* *}+M^{* *} .
\end{aligned}
$$

The first inequality follows from the fact that the harmonic mean never exceeds the arithmetic mean.

Proof of Corollary 10 Let $P=V_{2}$ and $V_{i}=V_{2}$ for all $i=3,4, \ldots, N$. Because

$$
\hat{V}_{N}=\frac{N V_{2}}{\frac{V_{2}}{V_{1}}+N-1},
$$

it follows that

$$
\frac{N-1}{N} \hat{V}_{N}=\frac{(N-1) V_{2}}{\frac{V_{2}}{V_{1}}+N-1}<V_{2}
$$

so that all parties will be active in the equilibrium without a secondary market. Now,

$$
\begin{aligned}
D^{*}+M^{*}-D^{* *}-M^{* *} & =\left(1+\frac{1}{N}\right)(N-1) \hat{V}_{N}-\sum_{i=2}^{N} V_{i}-\frac{N-1}{N} V_{2} \\
& =\left(1+\frac{1}{N}\right)(N-1) V_{2}\left[\frac{N}{\frac{V_{2}}{V_{1}}+N-1}-1\right] \\
& >0
\end{aligned}
$$

Because the inequality is strict, and all relevant functions are continuous, the result follows.

\section{References}

Allard, R. J. (1988). Rent-seeking with non-identical players. Public Choice, 57, 3-14.

Anderson, T. L., \& Hill, P. J. (1990). The race for property rights. Journal of Law and Economics, 33, 177197.

Barzel, Y. (1968). Optimal timing of innovations. Review of Economics and Statistics, 50, 348-355.

Barzel, Y. (1974). A theory of rationing by waiting. Journal of Law and Economics, 17, 73-95. 
Baik, K. H. (1994). Effort levels in contests with two asymmetric players. Southern Economic Journal, 61, 367-378.

Baye, M. R., Kovenock, D., \& De Vries, C. G. (1993). Rigging the lobbying process: An application of the all-pay auction. American Economic Review, 83, 289-294.

Bebchuk, L. A. (2001). Property rights and liability rules: The ax ante view of the cathedral. Michigan Law Review, 100, 601-639.

Che, Y.-K., \& Gale, I. L. (1998). Caps on political lobbying. American Economic Review, 88, 643-651.

Coase, R. H. (1960). The problem of social cost. Journal of Law and Economics, 3, 1-44.

Congleton, R. D., Hillman, A. L., \& Konrad, K. (Eds.). (2008). Forty years of rent-seeking research. Heidelberg: Springer (Two Volumes).

Dari-Mattiacci, G., \& Parisi, F. (2005). Rent, dissipation, and lost treasures: Rethinking Tullock's paradox. Public Choice, 124, 411-422.

Dari-Mattiacci, G., Langlais, E., Lovat, B., \& Parisi, F. (2007). Crowding-out in productive and redistributive rent-seeking. Public Choice, 133, 199-229.

Dasgupta, P., \& Stiglitz, J. (1980). Uncertainty, industrial structure, and the speed of R\&D. The Bell Journal of Economics, 11, 1-28.

Epstein, G. S., \& Nitzan, S. (2002). Asymmetry and corrective public policy in contests. Public Choice, 113, 231-240.

Epstein, G. S., \& Nitzan, S. (2007). Endogenous public policy and contests. Berlin: Springer.

Gahvari, F. (1989). Licensing and nontransferable rents: Comment. American Economic Review, 70, 906909.

Garratt, T., \& Tröger, T. (2006). Speculation in standard auctions with resale. Econometrica, 74, 753-769.

Glaeser, E. L., \& Luttmer, E. F. P. (2003). The misallocation of housing under rent control. American Economic Review, 93, 1027-1046.

Goeree, J. K., Maasland, E., Onderstal, S., \& Turner, J. L. (2005). How (not) to raise money. Journal of Political Economy, 113, 897-918.

Grossman, S. J., \& Hart, O. D. (1986). The cost and benefit of ownership: A theory of lateral and vertical integration. Journal of Political Economy, 94, 691-719.

Hafalir, I., \& Krishna, V. (2008). Asymmetric auctions with resale. American Economic Review, 98, 87-112.

Higgins, R. S., Shughart, W. F., \& Tollison, R. D. (1985). Free entry and efficient rent-seeking. Public Choice, 46, 247-258.

Hillman, A. L., \& Riley, J. G. (1989). Politically contestable rents and transfers. Economics and Politics, 1, 17-39.

Hirshleifer, J. (1989). Conflict and rent-seeking success functions: Ratios vs. difference models of relative success. Public Choice, 63, 101-112.

Hurley, T. M. (1998). Rent dissipation and efficiency in a contest with asymmetric valuations. Public Choice, 94, 289-298.

Jacklin, C. J. (1987). Demand deposits, trading restrictions and risk-sharing. In E. C. Prescott \& N. Wallace (Eds.), Contractual arrangements for intertemporal trade (pp. 27-46). Minneapolis: University of Minnesota Press.

Konrad, K. (2007). Strategy in contests-An introduction (WZB-Markets and Politics Working Paper No. SP II 2007-01).

Krishna, V. (2002). Auction theory. San Diego: Academic Press.

Krueger, A. O. (1974). The political economy of the rent-seeking society. American Economic Review, 64, 291-303.

Leininger, W. (1993). More efficient rent-seeking-A Münchhausen solution. Public Choice, 75, 43-62.

Lockard, A. A., \& Tullock, G. (Eds.). (2001). Efficient rent-seeking: chronicle of an intellectual quagmire. Dordrecht: Kluwer Academic.

Lott, J. R. Jr. (1987). Licensing and nontransferable rents. American Economic Review, 77, 453-455.

Lueck, D. (1995). The rule of first possession and the design of the law. Journal of Law and Economics, 38, 393-436.

Matros, A. (2006). Rent-seeking with asymmetric valuations: Addition or deletion of a player. Public Choice, $129,369-380$.

Mortensen, D. T. (1982). Property rights and efficiency in mating, racing and related games. American Economic Review, 72, 968-979.

Nash, J. (1950). The bargaining problem. Econometrica, 18, 155-162.

Nti, K. O. (1999). Rent-seeking with asymmetric valuations. Public Choice, 98, 415-430.

Onderstal, S. (2007). The optimality of ignoring lobbyists (Working Paper). University of Amsterdam.

Parisi, F. (2002). Entropy in property. American Journal of Comparative Law, 50, 595-632.

Posner, R. (1975). The social costs of monopoly and regulation. Journal of Political Economy, 83, 807-827.

Rubinstein, A. (1982). Perfect equilibrium in a bargaining model. Econometrica, 50, 97-109. 
Stein, W. (2002). Asymmetric rent-seeking with more than two contestants. Public Choice, 113, 325-336.

Suen, W. (1989). Rationing and rent dissipation in the presence of heterogeneous individuals. Journal of Political Economy, 97, 1384-1394.

Tollison, R. D. (2003). Rent-seeking. In C. K. Rowley \& F. Schneider (Eds.), Encyclopedia of public choice II (pp. 495-499). Dordrecht: Kluwer Academic.

Tullock, G. (1967). The welfare cost of tariffs, monopolies and theft. Western Economic Journal, 5, $224-232$.

Tullock, G. (1980). Efficient rent-seeking. In J. M. Buchanan, G. Tollison, \& G. Tullock (Eds.), Toward a theory of the rent-seeking society (pp. 97-112). College Station: Texas A\&M University Press.

Zardkoohi, A., \& Pustay, M. (1989). Does transferability affect the social costs of licensing? Public Choice, $62,187-190$. 